\title{
O PROCESSO EVOLUTIVO: UMA ANÁLISE SEMIÓTICA
}

Ana M aria de Andrade Caldeira*

Lauro Frederico Barbosa Silveira**

Resumo: Esta pesquisa é uma Análise Semiótica da Biologia Evolutiva, utilizando-se para tanto o quadro categorial de C harles S. PEIRCE (1853-1914). Q uestões como D iversidade, Acaso e Relações Ambientais são discutidas através de relações sígnicas.

Unitermos: Semiótica; D iversidade; Acaso; Relações Ambientais.

Abstract: This research is an Semi otic Analysis about the Evolutionary Biology, using the categorial scheme of CharlesS. PEIRCE (1853-1914). Q uestions C oncerning D iversity, C hance and Environmental Relations are discussed based on his theory.

Keywords: Semiotic; Diversity, Chance; Environmental Relations.

\section{O PROCESSO EVOLUTIVO: UMA ANÁLISE SEMIÓTICA}

A Biologia Evolutiva, área do conhecimento que procura reunir os resultados acumulados de diversas ciências como a biologia molecular, a genética de populações, a paleontologia, a sistemática de plantas e animais, a ecologia, conseguiu estabelecer de acordo com M AYR (1977) "o fato da evolução" mas resta ainda uma grande caminhada em saber como e porque ela ocorre.

Aristóteles foi um dos filósofos que teceu grande número de considerações biológicas e é sua, uma das primeiras indagações sobre a evolução dos Seres V ivos que se tem registro. M as uma idéia estruturada sobre Evolução vamos encontrar só por volta de 1852 com SPEN CER.

Em 1907, BERGSON publica a sua O bra-prima "L'Evolution Creative" onde discute as idéias de SPEN CER e coloca a sua noção de tempo como detentor da essência da vida e da real idade. Para ele, o tempo não podia ser somente o resultado de um momento sobre 0 outro mas acúmulo, crescimento, duração.

LAM ARCK, em seus estudos sobre evolução, chega à conclusão de que as característica dos seres vivos eram determinadas por força do hábito. E essas características poderiam ser passadas a seus descendentes.

Charles DARWIN é reconhecido no meio científico como o primeiro pesquisador sobre a Evolução, na obra "Origem das Espécies" de 1859 descreve pormenorizadamente suas observações sobre fauna e flora, e os experimentos que realizou ao longo de suas viagens. Antes dessa obra, a Evolução era alimentada por conceitos teóricos e não por experimentos, criticam os biólogos.

A síntese da teoria $D$ arwiniana é baseada no sucesso dos seres mais adaptados ao ambiente. As condições ambientais é que favoreceriam, através do sucesso reproduti-

\footnotetext{
* Professora Assistente D outora - D epartamento de Educação - Faculdade de Ciências - U N ESP - Câmpus de Bauru. (e-mail: caldeira@netsite.com.br)

** Professor Assistente D outor - Faculdade de Filosofia e Ciências - U NESP - C âmpus de M arília (email: lauro@art.com.br)
} 
vo diferencial, aqueles indivíduos que apresentassem características que facilitassem a sua vida em determinada ambiente. Criticada por muitos, utilizada de forma equivocada por ideologias que pretendem justificar as injustiças sociais, em nome da sobrevivência dos mais aptos, modificada por outros, mas resistente ao tempo. Representa nos dias atuais a base de discussão para novas pesquisas que tratam esse tema.

$\mathrm{N}$ a segunda metade do século XX, a Biologia Evolutiva passou a concentrar sua atenção nas descobertas que ocorriam em nível molecular, principalmente nos processos de funcionamento e regulação do gene.

Com base no aprofundamento dos mecanismos de funcionamento molecular, podemos atualmente, falar em U ma Teoria Sintética da Evolução fundamentada nos conceitos de mutação, recombinação e Seleção N atural. ST EBIN S (1970), dentro desses conceitos, reconhece cinco processos básicos atuando na evolução das espécies: "M utação G ênica, Variações na Estrutura e no N úmero de Cromossomos, Recombinação G ênica, Seleção N atural e Isolamento Reprodutivo". ${ }^{1}$

Apesar do longo caminho de progressos que a Biologia Evolutiva percorreu, quer no campo das descobertas moleculares, físicas e químicas, quer no debate filosófico, ainda não conseguimos responder às perguntas formuladas há milênios. E a dúvida essencial de como os processos biológicos são controlados ou não, persiste.

Para ampliar e aprofundar a análise dos fenômenos que envolvem as teorias evolucionistas e a organização dos ambientes naturais, nos apoiamos no referencial teórico da filosofia de Chalers Sanders PEIRCE (1839-1914). 0 trabalho de PEIRCE, baseado na pesquisa científica e na lógica é muito vasto e nos centramos em sua teoria sígnica.

A teoria Peirceana dos signos é baseada na convicção de que a relação sígnica é fundamentalmente triádica: a relação entre signo (representam) objeto e interpretante.

A definição de signo abaixo é uma das muitas que o autor produziu:

"D efino um Signo como qualquer coisa que, de um lado, é assim determinado por um objeto e, de outro, assim determina uma idéia na mente de uma pessoa, esta última determinação, que denomino o Interpretante do signo é, desse modo, mediatamente determinada por aquele objeto. Um signo, assim, tem uma relação triádica com seu objeto e com seu Interpretante.". (CP 8.343)

\section{E onde aplicar a definição de signo dentro dos fenômenos biológicos?}

Para PEIRCE, a definição de signo pode ser amplamente aplicada pois para ele "o universo inteiro está permeado de signos, se é que ele não é composto apenas de signos". (CP 5.448)

$\mathrm{N}$ a teoria de PEIRCE, o conhecimento faz-se mediante signos e no decorrer da experiência, SI LVEIRA (1988) analisa o signo como forma mediadora entre a conduta e 0 objeto.

"a independência do objeto e sua exterioridade ou quase exterioridade relativamente ao sujeito que conhece, sua necessária alteridade como garantia da liceidade do conhecimento, projetam necessariamente no futuro tendencial a obtenção da verdade por uma comunidade. Esta comunidade

1 ST EBIN S - Adaptive Shifts Toward H ummingbird Pollination em The Evolutionary Ecology of Plants - Bock e Linhart (orgs.) - Westiew Press, 1989, 660 p. 
com efeito, constitui a única instância capaz de efetivamente superar a particularidade que limita a individualidade e a soma das individualidades. Realiza, no interior do possível histórico, a totalidade que a generalidade, atributo essencial do pensamento e da lei, exige."

Para a compreensão desse estudo, torna-se necessário que entendamos aqui os processos comunicativos que percorrem todo o universo vivo. SEBEOK (1993) diz que:

"A comunicação - transportada inicialmente pelo código molecular primordial, sujeita a uma contínua mudança qualitativa e quantitativa dos segmentos genéticos e, posteriormente, transportada pela rede imunológica de células que operam através de substâncias mediadoras ativas - énecessariamente uma propriedade de toda e qualquer forma de vida. ...a comunicação está presente nas formas mais humildes de existência, sejam elas bactérias, plantas, animais ou fungos."

Pensando a natureza de forma global, partimos do pressuposto, que a natureza também tem seu objeto que busca incessantemente, ou seja, a manutenção da vida. Esse seria seu desejo, ensaiado e experimentado há bilhões de anos, trocando as espécies, modificando 0 ambiente à procura das formas de vida que melhor se harmonizem entre si e possam assegurar a manutenção do seu objeto desejado.

Poderíamos classificar a natureza como uma experimentadora sem descanso que cria e transforma mecanismos que possibilitem manter constantemente o seu fazer experimental. Tal processo é revestido de sutileza representada pelo tempo, às vezes bilhões de anos, que uma determinada forma de vida leva para evoluir e se adaptar.

É o ser vivo que, possuidor de determinadas características que adquiri ao acaso e consegue sobreviver a uma mudança ambiental, ou a natureza provêm a espécie de tantas possibilidades adaptativas, para que ela de qualquer forma sobreviva? $\mathrm{O} u$ a conjugação de fatores como potencial genético, tempo e espaço, entendido aqui como o conjunto ambiental, que atuam permitindo que al guns seres sobrevivam e transmitam sua carga genética e outros não? Como poderíamos entender uma cadeia de signos percorrendo o processo evolucionário?

Para que possamos iniciar uma análise na tentativa de buscar subsídios para essas perguntas, traçamos um diagrama com base nas três categorias de PEIRCE, ou seja, a Primeiridade, Secundidade e Terceiridade, distribuindo em seu interior os elementos que compõem a Teoria Sintética da Evolução.

A idéia que se apresenta é munir-se dessas categorias fenomenológicas, procurando estabelecer relações entre as variáveis, que de acordo com a maioria dos biólogos, compõem os processos evolucionários. Além da forma

de entender a Evolução, como propõe a Teoria Sintética, procuraremos levar em consideração outras idéias que começam a tomar corpo no meio científico, como por exemplo, a teoria da auto-regulação.

\footnotetext{
2 SILVEIRA - L. F. B. - 0 caráter D ialógico e Social do Signo e do Pensamento em Peirce - Trans / Form / A ção 11: 23-29. 1988

3 Sebeok, T. A. (1993) apud - SAN TAELLA e NÖTH (1966) - O s estudos da Linguagem e do Signo - Em o Falar da Linguagem, Ed. Lovise, p. 78
} 


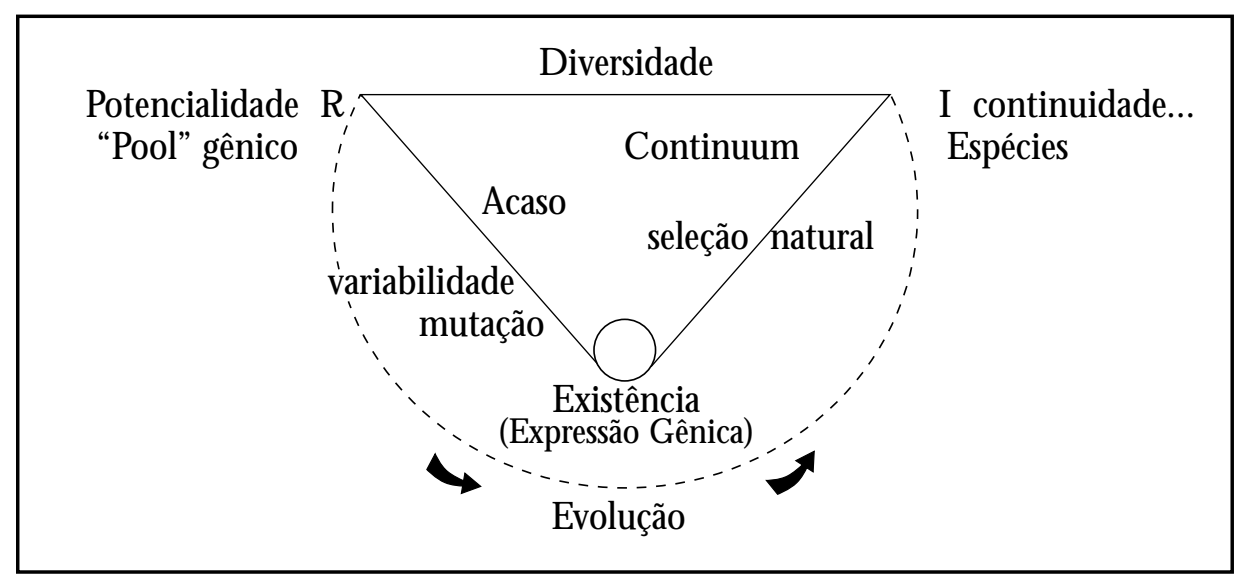

Para análise desse diagrama de forma total, é preciso levar sempre em conta as relações de primeiridade, secundidade e terceiridade que o signo necessita para se expressar.

Podemos inferir que o "pool gênico", colocado como primeiridade, expressa a potencialidade de vida que a natureza dispõe. Um quali-signo.

A expressão gênica, representaria a existência concreta, a ocorrência e interação no espaço / tempo que nessa relação didática pode ser identificada como um sin-signo.

0 legi-signo estaria representado pela continuidade genética, presente em cada indivíduo de uma espécie, tomando o caráter de lei ou regra geral que esse tipo de signo exige.

U ma vez classificado os signos dentro desse diagrama, algumas relações podem ser analisadas. Para tanto procuramos comparar esse estudo com os conceitos que compõem a Teoria Sintética da Evolução, subsidiando assim, essa discussão.

Se colocarmos uma especial atenção aos fenômenos naturais, podemos observar que uma série deles têm sua ocorrência atribuída ao Acaso. Podemos citar alguns exemplos. Fecundação e Reprodução dependem do Acaso para que dois gametas se encontrem, se reproduzam num novo ser. Se atentarmos para a ocorrência desses dois processos, em plantas, podemos salientar, usando as angiospermas para tanto, os passos que são necessários.

- É necessário que uma flor se forme na extremidade de algum ramo.

- Para que essa flor seja polinizada deve ocorrer a presença de abelhas, pássaros ou o vento que traga pólen de uma outra flor. Bock e Linhart (1989) salientam que a coloração das flores e os seus odores são sinais utilizados pelas plantas para atrair seus polinizadores. Relatam também que o néctar das plantas não é apenas um líquido açucarado que alimenta temporariamente o sugador. $M$ as, há em sua composição, uma complexa mistura de carboidratos, aminoácidos e substâncias tóxicas que exercem a função de atrair visitantes específicos e desencorajar outros.

- Um fruto começa a desenvolver-se a partir da flor polinizada, produzindo substâncias para que a semente recém formada sobreviva.

- U ma vez maduro, os frutos são levados pelo vento ou são dotados de ganchos que grudam em pêlos dos animais e são assim transportados, outros são vistosos atraindo pássaros e herbívoros que defecam suas sementes em locais distantes da planta-mãe; há também exemplos como o coco da Bahia, que sobrevive por tempo no mar sendo levado para outras praias. 
- Assim que encontram local favorável, essas sementes começam a germinar, crescer, enfrentar as condições ambientais e o processo repete-se.

0 mesmo detal hamento poderíamos resgatar, se voltássemos nossa observação para a reprodução sexuada entre os animais. Mecanismos complexos de corte, plumagem, canto, espreita, só para citar al guns, desenvolveram-se para facilitar o encontro do macho e da fêmea. Ao longo da evolução surgiram também entre indivíduos de algumas espé cies, sinais-estímulos al tamente específicos entre o macho e a fêmea, como a sincronização dos ciclos hormonais guiando o comportamento ao acasalamento e também o paternal, como 0 descrito em pombo - trocaz por DELTH IER e ST ELLAR (1973).

Diante do desenvolvimento desses sinais, que facilitam e conduzem a reprodução em algumas espécies de plantas e animais, poderíamos questionar essa ocorrência fortuita, atribuída unicamente ao Acaso. Esses mecanismos de facilitação para que a reprodução ocorra de forma específica, não diminuiria o papel do Acaso? 0 grande número de sementes produzidas por uma planta, relativas à cada espécie, a proteção das sementes, as inúmeras chances de dispersão e futura germinação, não falariam contra a idéia de responsabilizar 0 Acaso por toda diversidade e variedade encontradas na natureza?

A biologia molecular e o estudo gênico desenvolveu-se de maneira extraordinária devido em grande parte às técnicas que permitiram a manipulação do material genético.

Por essas técnicas já é possível saber que algumas seqüências de DNA evoluem em taxas muito mais elevadas que outras. 0 código genético apresenta-se maior degeneração na terceira posição e menor na segunda, apoiando argumento de alguns pesquisadores de que a fixação da maioria das substituições nucleotídicas é conseqüência da deriva genética causal em vez de seleção natural (FUTU YAM A 1992). D escobriu-se também que ligações entre genes evoluem por rearranjos cromossômicos como inversões, translocações, fusão e quebra de cromossomos. O bservou-se que a quantidade de D N A é bastante elevada nos processos de poliploidia.

Epissomos, transposons, plasmídeos - são seqüências de D N A que podem ser duplicadas e inseridas em muitas regiões do genoma. Podem causar mudanças adaptativas nos cromossomos que estão inseridos como é o caso de resistência à drogas em bactérias conseguidas pela presença de plasmídeos que transportam esse gene.

O s processos de duplicação e união interna nas seqüências de D N A podem originar enzimas com novas funções. A variação mutacional adaptativa na estrutura e regulação das enzimas é uma importante característica da evolução. (FUTU YAM A, 1992).

Tal avanço no entanto ainda não nos permite saber com segurança como 0 gene eucariótico se expressa. "Q uanto mais sabemos a respeito da regulação gênica eucariótica, mais fica claro que os genes eucarióticos são controlados em inúmeros níveis. ${ }^{4} \mathrm{M}$ as essas pesquisas, embora ainda não conclusivas, começam a apontar para os mecanismos que ocorrem à nível molecular, respostas e comportamentos até então atribuídos à ocorrência do Acaso. A diminuição da hegemonia do A caso na constituição da variedade e diversidade presentes na natureza começa apenas a delinear-se mas de forma consistente. H egemonia essa talvez mantida, por absoluto desconhecimento desses processos.

D essa forma o continuum espaço/tempo influenciaria de modo decisivo o existir de cada indivíduo, formando junto com o potencial genético, o indefinido geral. 
Expressa na segundidade do ser, a semiose que se completaria com o elemento da terceiridade, no caso a continuidade da vida, que se efetua através das gerações. A ação do continuum espaço/tempo teria uma ação mediata ao nível do indivíduo e uma imediata ao longo da espé cie, constituída pela pluralidade de individuais, garantindo através do continuum espaço/tempo, a continuidade da vida.

Dentro da Semiose formada, podemos identificar claramente o papel da primeiridade, o potencial genético que é influenciado pelo acaso e talvez outras variáveis. A secundidade está representada pela existência de qualquer ser vivo, em conjunto com a ação do espaço e tempo. E a terceiridade, completando-se na continuidade da vida. Resta ainda uma pergunta. Se sabemos que o espaço, - ou seja, as condições ambientais - atua ora contribuindo para a manutenção da vida, ora dificultando-a com situações desfavoráveis, facilitando o papel selecionador da natureza, como agiria o tempo?

Se espaço e tempo tomam parte da ação, o potencial genético,

concretizado em um ser vivo, é apenas um elemento que compõe os fatores que atuam para o sucesso de um indivíduo e consequentemente na sua pluralidade, da espécie. Tempo e espaço são co-responsáveis ao processo contribuindo na eliminação ou na fixação de um grupo de genes.

\section{A EVOLUÇÃo}

Voltando ao nosso diagrama inicial podemos ler que um cursor imaginário se mova no sentido da Potencialidade ao da Continuidade passando pela Existência. Teríamos a produção do processo Evolutivo que se instaura no decorrer das gerações em conjunto com espaço e o tempo. Instala-se aí uma verdadeira semiose que se processa num vasto domínio, desvinculado da palavra, mas que apoiado no quadro categorial proposto por PEIRCE, como analisa SILVEIRA (1996) acaba por dotar a matéria, essa rede complexa de relações, de um caráter estritamente lógico.

D esse modo poderíamos entender a natureza como al go ou alguém que utiliza seus recursos amplamente, que usa o D N A como o seu signo - pensamento, que expressa a vida, mas também muda, inova e extingue a vida. $\mathrm{N}$ ão se pode pensar separadamente em potencial gênico e ambiente. Entende-se como um processo único onde a tradição é mantida de geração em geração, mas não integralmente. C ada vida tem a possibilidade de recombinar-se sempre de testar algumas mudanças, às vezes com sucesso e a responder aos estímulos ambientais. Para manter essas possibilidades desenvolveu os sistemas de regulação gênica, que variam conforme cada espécie, passando dos arranjos moleculares simples, como os do vírus até os complexos sistemas de diferenciação celular, que encontramos nos grupos mais desenvolvidos.

A vida, que além de gerar, pode permitir ou facilitar a existência de outras vidas, como nos processos de simbiose, parasitismo e em última análise o predatismo, ou ainda preparar o ambiente para outras espécies, como nos processos fotossintéticos ou das plantas pioneiras que enfrentam o solo árido para permitir a instalação de outras espécies, pode ser vista como uma busca constante de equilíbrio perfeito.

As alterações ambientais que são resultados do rompimento desse equilíbrio, ocasionando às vezes o desaparecimento de populações inteiras, são seguidas de um lento e gradual processo de recomposição das perdas ocorridas.

M uitas vezes a natureza não consegue repor uma ou outra espécie que o dese- 
quilíbrio fez com que desaparecessem, mas acena com novas espécies, potencialmente aptas, que possam viver nesse ambiente modificado e gerar novamente a vida.

Assim o processo evolutivo não seria regido pelo acaso da ocorrência de mutações que 0 ambiente seleciona mas uma auto-organização da natureza frente a desequilíbrios surgidos. APEL diria que no começo há espontaneidade e então a "natureza se autoorganiza e se sedimenta em leis que são resultado do tempo e da evolução". ${ }^{5}$

\section{Referências bibliográficas}

APPEL, K. O. Entrevista Jornal "O Estado de São Paulo" - 07/09/1996.

BOCK, J. H .; LIN H ART, Y. B. The Evolutionary Ecology of Plants. Westiew Press, 1989, $660 \mathrm{p}$.

DELTH IER, V. G.; STELLAR, E. Comportamento Animal. São Paulo: Edusp, 1973, $151 \mathrm{p}$.

FUTUYAMA, D. J. Biologia Evolutiva. Sociedade Brasileira de Genética/CN Pq, 1992, $646 \mathrm{p}$.

M AYR, E. Populaç̧ões, Espécies e Evolução. Cia. Ed. N acional, 1977, 485 p.

PEIRCE, C. S. estão indicadas no texto, conforme 0 usual a esta obra C.P. indica Collected Papers; o primeiro número corresponde ao volume e o segundo ao parágrafo.

SILVEIRA, L. F. B. 0 Caráter D ialógico e Social do Signo e do Pensamento em Peirce. São Paulo: Trans / Form / Ação, v. 11, 1988, p. 1-24. - A I conicidade do Signo Lingüístico e Algumas de suas conseqüências. 0

Falar da Linguagem, São Paulo, oㅡ. 1, Ed. Lovise, 1996, p. 71-85.

SEBEO K, T. A. (apud SANTAELLA, L. NÖTH, W.) Os estudos da Linguagem e do

Signo. O Falar da Linguagem. São Paulo, №. 1. Ed. Lovise, 1996, p. 71-85.

ST EBIN S - Adaptive Shifts Toward Hummingbird Pollination em The Evolutionary

Ecology of Plants - Bock e Linhart (orgs.) - Westiew Press, 1989, 660 p. 